\title{
A Government Subsidy Model for Expressway Public Private Partnerships Projects Based on Project Revenue Features and Whole Life-cycle Management
}

\author{
Yihua $\mathrm{Li}^{1}$, Chunchao $\mathrm{Chu}^{2, *}$, Yanzhen $\mathrm{Weng}^{2}$ and Jia Song ${ }^{2}$ \\ ${ }^{1}$ Department of Transport of Guangxi Zhuang Autonomous Region, Nanning, China \\ ${ }^{2}$ China Academy of Transportation Sciences, Beijing, China
}

\begin{abstract}
Popularisation and application of Public Private Partnerships (PPP) model is an important measure used to deepen the investment and financing reform of China. The transportation industry actively explores and promotes the wide application of PPP models as they have injected new impetus into the construction and development of transportation investment. For PPP projects of expressways that are subsidised by government in the construction or operation period, since the traffic flow in the project construction period or the early operation period is low, the government subsidy is more concentrated and the payments are high, which aggravates pressure on the fiscal purse in the current period and is not conducive to the realisation of smooth fiscal expenditure in the project cooperation period. In this regard, aiming at the features of the investment revenue of expressway projects, a whole life-cycle government optimisation of subsidy mode is proposed through the analysis of the problems existing in the general subsidy mode of the PPP model in the present work. The results show that the proposed model can not only smooth government expenditure in the project's cooperation period, but also fully exploit the advantages of higher income in the middle and later stages of project operation and maximise the growth potential of government revenue. The results of the research can provide decision-making reference for the development of innovative PPP models for transportation infrastructure in the new Era.
\end{abstract}

\section{Introduction}

Expressway construction projects have a large investment scale and long investment cycle. At present, most new expressway projects are located in remote and poor areas, in which the traffic volume is low, and where construction costs are rising. It is already difficult for project investors to achieve reasonable returns on their investment by relying solely on user fees. At this point, the project is implemented using the PPP model, which enables the project to achieve economic viability by government giving investors a certain construction investment subsidy or operating gap subsidy. Popularization and application of PPP model are an important measure to deepen the investment and financing reform of China, and it can better play the decisive role of the market in the allocation of resources and continuously improve the effective supply of public services and infrastructure ${ }^{[1-2]}$. For government, on the one hand, it can not only reduce fiscal pressure through investment in expressway infrastructure construction, but also give full play to the rich project management experience of social capital and the efficiency of market-oriented operation of project companies to improve the supply efficiency of transportation infrastructure ${ }^{[3]}$; on the other hand, the concentrated amount of gap subsidies caused by low traffic flow during the construction period or the initial operating period of the project will increase pressure on the fiscal purse, which is not conducive to smoothing of fiscal expenditure during the project's whole life-cycle. In this regard, based on the analysis of the problems prevailing in the general subsidy mode of the PPP model, aiming at the features of the investment revenue of expressway projects, we propose a whole life-cycle government optimization mode of subsidy. This can not only smooth government expenditure in the project's cooperation period, but also fully exploit the advantages of higher income in the middle and later stages of project operation and the growth potential of government revenue.

\section{Analysis of Investment and Revenue Features of Expressway Projects}

In recent years, the transport industry has played an important role in raising funds for transport infrastructure development through multiple channels, optimising the allocation of the investment structure and enhancing the supply of transport public products and services by vigorously promoting the application of the PPP model, thus making an important contribution to the deepening of transport reform, high-quality development, and the

*E-mail: chucc@motcats.ac.cn 
construction of a strong transport-based country ${ }^{[4-5]}$. As one of the key areas to promote the application of the PPP model, expressways are not only related to the continuous improvement of national PPP policies and advocacy for its implementation but are also closely related to the attributes and characteristics of expressway projects. Specifically speaking, expressways have the following features in terms of investment and revenue:

The investment scale of individual expressway project is large, and its economic benefits are poor. According to the PPP Centre of the Ministry of Finance, by the end of February 2021, there are 1,374 transportation projects in the PPP project management database, with a total investment of 5,164.8 billion yuan, and the average investment in individual transportation projects is 3.76 billion yuan. Statistics also show that in 2019 , the toll highway mileage of China is $142,800 \mathrm{~km}$, with toll revenue of 555.1 billion yuan and total expenditure on debt servicing, maintenance, and management of 102.25 billion yuan, with an average annual gap of 3.27 million yuan $/ \mathrm{km}$. The investment cost per kilometre of expressway is generally above 100 million yuan, and the investment returns of motorway projects are generally poor, which often requires government to give certain investment subsidies or financial support, and then investors may earn certain construction-derived profits to offset the project investment risk by participating in the construction of the project.

Expressway projects are characterised by long payback periods and low returns on investment in the early years of operation. According to the current Regulations on the Administration of Toll Roads, the longest toll collection period for PPP projects on expressways is no more than 25 years in eastern regions and no more than 30 years in central and western regions. Compared with the concentrated investment during the project construction period (2-3 years), it is necessary to recover the investment and obtain reasonable return within the operating period (25-30 years), and the project return period is thus longer. Moreover, in the initial period of operation (3-6 years), the traffic flow is low, and project toll revenue is generally very low, which requires a large amount of short-term financing capital and puts greater pressure on the likely success of the project and its operation.

In the later operation stage of expressway operation, the cash flow is stable and abundant. After one expressway project has been constructed and put into operation, with the continuous improvement of regional road network and socio-economic development along the route, the project traffic flow increased, entering a higher and stable stage after its initial growth, the toll revenue stabilises at a much higher level, and the project begins to generate continuous profit. According to related statistics, we can divide the expressways completed and opened to traffic between 1996 and 2017 into seven segments, each covering a time period of three years. That is: the average annual toll revenue of projects completed and opened to traffic for $1-3$ years is 1.42 million yuan $/ \mathrm{km}$, for 4-6 years is 2.46 million yuan $/ \mathrm{km}$, for 7-9 years is 3.54 million yuan $/ \mathrm{km}$, for $10-12$ years is 4.45 million yuan $/ \mathrm{km}$, for 13 -
15 years is 6.15 million yuan $/ \mathrm{km}$, for $16-18$ years is 7.35 million yuan $/ \mathrm{km}$, and for $19-21$ years is 8.94 million yuan $/ \mathrm{km}$. This indicates that annual toll revenue from expressways tends to increase steadily over time of operation and that the cash flow of toll revenue from projects in the later stages of operation is both stable and abundant.

The risk of projects is high, then low, and returns are low, then high throughout the project life-cycle. Expressway projects have a long construction (2-4 years) and operation ( 25 to 30 years) phase, during which they usually face a series of risks such as cost overruns in land acquisition and demolition, price increases in construction materials, construction technology and design changes, high uncertainty in traffic volume forecasts, and significant effects from policy adjustments (e.g. implementation of a free-pass policy), and in particular the early construction and operational risk is bigger. The whole cooperation period is characterized by high risk and then a low risk, and returns are low and then high, which requires long-term cooperation between governments and investors to allocate risks and share investment returns reasonably throughout the whole life-cycle.

\section{Traditional Government Subsidies and their Existing Problems}

In a PPP project aimed at building an expressway, the expenditure responsibility of governments is mainly reflected in two aspects: on one hand, the equity funds contributed by governments and their subsidy during the construction period; on another hand, the feasibility gap subsidy and the minimum demand subsidy for the vehicle flow provided by governments during the operating period. Among them, the equity capital contributed by governments in the construction period is calculated according to the proportion of the project equity capital and the government's proportional shareholding in the SPV, and the subsidies in the construction period are disbursed according to actual expenditure on the parts of the project and government. The subsidy for the minimum demand of vehicle flow shall be provided by government according to the comparison between the actual vehicle flow of the project operation and the predictable vehicle flow of the project; the feasibility gap subsidy in the operating period is key to the design of the PPP project government subsidy mode, which is generally calculated based on the project cash flow method, that is, the net cash flow of each year in the whole life cycle of projects. The calculation model is shown in Formula (1).

$$
\sum_{t=1}^{n} \frac{A_{t}-B_{t}}{(1+i)^{t}}=0
$$

where, $A_{t}$ is the cash inflow in the current period of the $t^{\text {th }}$ year of the project cooperation period; $B_{t}$ is the cash outflow for the current period of year $t$ of the project cooperation period; $n$ denotes the total number of years calculated on an annual basis for the project cooperation period; $i$ is a reasonable rate of return for the project, to be determined by the government in consultation with social capital standards or through bidding.

$$
A_{t}=A_{t 1}+A_{t 2}+A_{t 3}
$$


where $A_{t 1}$ is the toll revenue for the current period of the $t^{\text {th }}$-year project cooperation period; $A_{t 2}$ is the operating income of the current period of the $t^{\text {th }}$-year of the project cooperation period, in addition to tolls, including advertising, service areas, etc.; $A_{t 3}$ is the feasibility gap subsidy fund granted to the project during the current period of the current government in the $t^{\text {th }}$-year of the project cooperation period, and to smooth the financial expenditure, it is generally constant during the cooperation period.

$$
B_{t}=B_{t 1}+B_{t 2}+B_{t 3}+B_{t 4}
$$

where, $B_{t 1}$ is the investment expenditure of the current project construction in the $t^{\text {th }}$-year of the project cooperation period; $B_{t 2}$ is the principal and interest expense of the loan to be repaid in the current period of the $t^{\text {th }}$-year of the project cooperation period; $B_{t 3}$ is the current operating expenses for the $t^{\text {th }}$-year of the project cooperation period, including the project overhaul and daily maintenance, management fees, etc.; $B_{t 4}$ is the current tax expense in the $t^{\text {th }}$-year of the project cooperation period, including VAT, income tax, etc.

For an expressway PPP project, the traditional government subsidy mode in the operating period (including the feasibility gap subsidy and minimum demand subsidy of traffic flow) is based on the predicted traffic flow and project revenue and expenditure data. On this basis, according to the requirements of smooth financial expenditure, the government subsidy in the operating period of the project is calculated by using formula (1); however, by observation, the initial traffic flow is often less than that predicted, which makes the government's actual expenditure on subsidies increase in the initial stage of operation. In the later stage of operation, with the continuous improvement of the road network and regional socio-economic development, the traffic flow increases rapidly, and the project income grows therewith. Therefore, from the whole project cooperation period, due to the increase of government subsidy expenditure in the early stage, the government subsidy will decrease in time ${ }^{[6-8]}$. On the one hand, there is no smooth financial expenditure, which aggravates the pressure on current government financial outgoings, and allocates the larger share of the project investment risk to the government in the early stage of operation. On the another hand, it does not match the project income characteristics and the growth of government financial revenue in the operation period, and does not give full play to the role of large investment, the long cycle, and stable income of expressway projects, and cannot fully realise the potential advantages of high-income dividends and continuous growth of financial revenue in the later stage of project cooperation.

\section{Government Subsidy Mode Based on Project Income Characteristics and Whole Life-cycle}

Considering that, on one hand, after the completion of expressway, with the gradual improvement of the expressway network, the toll income from expressway projects will increase year-on-year: because the project has significant socio-economic benefits, it will drive the development of industries along the route, and then increase local fiscal revenue, so that the government's financial payment capacity will continue to improve. On another hand, using the idea of "time for space", lengthening the implementation cycle of government subsidies in the operation period, extending the traditional mode from the period of poor project income in the initial stage of subsidy to the period of integrated project cooperation, can alleviate the pressure of financial centralised payment. Based on the above considerations, this innovation in the present work lies in the design of government subsidies during the operation period, and the proposed government subsidy mode based on the characteristics of project income and the whole life-cycle. On the premise of ensuring smooth financial expenditure during the project cooperation period, it guides those responsible for project expenditure to adapt to the characteristics of project income and the growth potential of financial revenue, and reasonably resolves the issue around current financial expenditure pressure. The model of the feasibility gap subsidy fund provided by the current government in the operation period of the project in the $t^{\text {th }}$-year of the project cooperation period is shown in formula (4).

$$
\left\{\begin{array}{rr}
A_{3}(1+\beta)^{t-1} & A_{t 3}<M \\
A_{t 3} \geq M
\end{array}\right.
$$

where $A_{3}$ is the feasibility gap subsidy fund given by governments in the first year of the project cooperation period; $\beta$ denotes the increase in proportion of subsidy funds in subsequent cooperation years, it can be generally determined by referring to the growth rate of local financial revenue in the previous five years; $M$ represents the maximum annual subsidy provided by government during the operation period, which can be determined by competitive bidding.

In this mode, the annual growth and change of financial revenue in the project location are fully considered, and the gap subsidy provided by the government during the operating period is fully matched with that in the project cooperation period. A large part of the government subsidy expenditure responsibility is transferred to the middle and late stage of the project's operation, reducing pressure on government financial expenditure in the early stage of the project completion and operation. Upon completion of the project and the continuous improvement of the road network, the local socio-economic development will be promoted, and the financial situation of the government will continue to improve, which can also resolve the issue around financial payment pressure in the future.

It should be noted that the expressway PPP model, based on this model, will require less government subsidies than the traditional model operating in the early stages, however, while reducing the pressure on government expenditure, it is possible that in the early stages of project operation, the project company's toll revenue and subsidy income cannot meet service the debt, necessitating short-term borrowing. This increases the 
operating costs of the project company and reduces the attractiveness of social capital. Therefore, it is necessary to assess the relationship between the pre-project toll income and the subsidy income and the debt service expenditure, and if necessary, to adjust the pre-subsidy income $A_{3}$ so that the project income can meet debtservice requirements.

\section{Application Cases for New Models}

An expressway PPP project, with a total length of about $74 \mathrm{~km}$, is built to two-way, four-lane highway standard, with a design speed of $80 \mathrm{~km} / \mathrm{h}$ and an estimated total investment of 12.297 billion yuan. The project adopts the mode of cooperation based on "equity cooperation and BOT-EPC-operating period government subsidy", with a cooperation period of 33 years, of which the construction period is 3 years and the operating period is 30 years. The project capital ratio is $25 \%$ of the total investment, funded

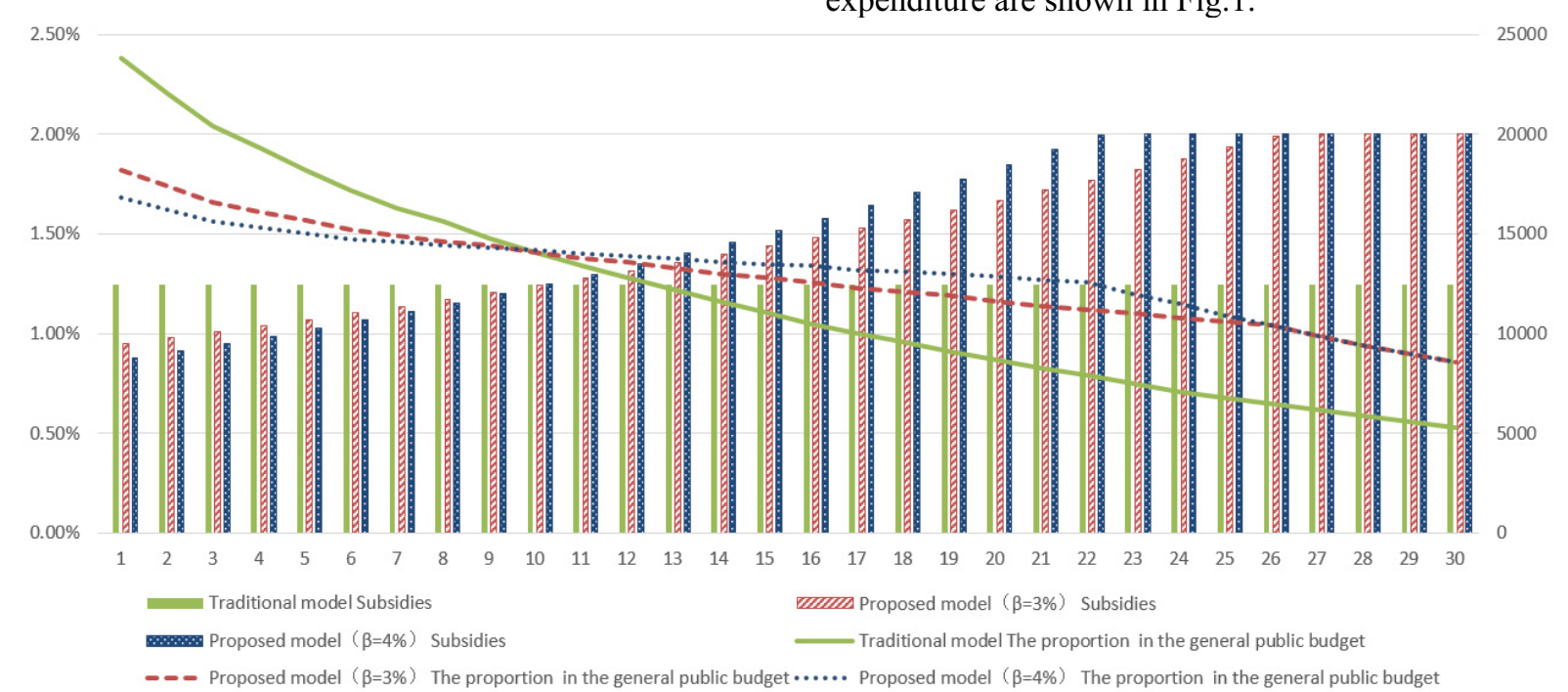

Figure 1. Annual subsidy and its proportion of general public budget expenditure under the traditional and new models

The results show that, compared with the traditional model, the operating subsidy is lower in the initial stage of the project operation under the new model, which accounts for a small proportion of the general public budget expenditure, thus relieving the pressure on current fiscal expenditure, so that more financial resources can be released for other projects under the same conditions, and the financial benefits maximized. Moreover, it can also be seen from the ratio curve of subsidy to general public budget expenditure that the curve under the new model tends to be smoother.

\section{Conclusions and Prospects}

The government subsidy in the traditional model is more concentrated and the payments are high, which aggravates pressure on the fiscal purse and is not conducive to the realisation of smooth fiscal expenditure in the project cooperation period. Aiming at the large investment in expressway projects, the concentration of investment during the construction period (generally 2-3 years), the long operating period (generally 25-30 years), in which the income presents the characteristics of increasing after by the government and investors in the ratio of 3:7: the rest of the funds are raised through bank loans and other channels. Funds are invested at a rate of $30 \%, 40 \%$, and $30 \%$ in each year during the construction period. According to project team reporting, the project operating period of 30 years will lead to toll revenue to a total of 35.448 billion yuan, operating costs of a total of 2.044 billion yuan, including small and medium-sized repairs and daily maintenance costs, overhaul costs, financial management costs. The growth rate of the project's local fiscal revenue is determined by an average growth rate of $5 \%$ over the previous five years.

Under the same conditions as the relevant boundaries, based on the traditional government subsidy model and the newly proposed subsidy model (sub- $\beta=3 \%$ and $4 \%$, the maximum annual subsidy $M$ for the operating period is 200 million yuan), the project operating period subsidy is measured, the amount of subsidy for each year of operation and the proportion of general public budget expenditure are shown in Fig.1.

the previous low, we proposed a whole-life government optimisation subsidy model suitable for the project income characteristics. This makes the fiscal expenditure curve smoother during the project cooperation period.

\section{References}

1. Jia Kang. PPP: Institutional Supply Innovation and its Positive Effects[J]. China's Strategic Emerging Industries, 2016 (26): 26-29

2. Shi Yaobin. Promoting PPP Model is an Important Part of Supply Side Reform[J]. China Economic Weekly, 2015, 000 (050): 35-37

3. Wang Kun. Research on PPP in Transportation Infrastructure Construction[D]. Shandong Normal University, 2019

4. Li Caixia. PPP Model innovation and Practice of Transportation Infrastructure Projects[D]. Chongqing Jiaotong University, 2017

5. Cui Yuanyuan. Research on the Transformation of Government Functions Promoted by PPP Model in 
the Field of Infrastructure[D]. Nanjing University, 2017

6. Song Chaoqun, Wang Kai, Hou Lixing. Research on Calculation Method of Feasibility Gap Subsidy for Expressway PPP Project[J]. Transportation Science and Technology and Economy, 2019, 21 (4): 75-80

7. Zhu Xiaoyan, Zhang Yin. Analysis and Application of Calculation Formula for Feasibility Gap Subsidy of Expressway PPP Project[J]. Highway Transportation Science and Technology, 2018

8. Gao Jianing, Zhao Jiafa. Investment Decision Analysis of Expressway PPP Project Considering Feasibility Gap Subsidy[J]. Traffic Finance and Accounting, 2020, 393 (4): 9-13 